\title{
ESTRATÉGIAS DISCURSIVAS: UM RECORTE DIALÓGICO DA AULA
}

\section{DISCURSIVE STRATEGIES: A DIALOGICAL CUT FROM A CLASS}

\author{
Ester Maria de Figueiredo Souza ${ }^{1}$
}

Islene dos Santos Roque Benevides 2

Recebido: 02 fev. 2019

Aceite: 05 abr. 2019

DOI https://doi.org/10.29327/2.1373.1-2

RESUMO: Este artigo objetiva compreender como se constituem as interações na aula de produção textual e a natureza das réplicas nos enunciados de professor e alunos conformados com o uso dos gêneros de ensino. Essa discussão está fundamentada na teoria dialógica de Bakhtin (1981, 1997), da qual enquadramos a noção de compreensão responsiva, conformando-a na Linguística Aplicada. Para a análise do corpus, utilizamos a observação participante, gravação em vídeo e atividades do livro didático: "Português: Linguagens - v. 3" (CEREJA E MAGALHÃES, 2012), bem como outras tarefas escolares aplicadas pela professora. Os resultados evidenciaram a presença de enunciados reiterativos que se revelam como estratégias replicantes constitutivas dos movimentos dialógicos.

PALAVRAS-CHAVE: Compreensão responsiva; Dialogismo; Produção textual.

\begin{abstract}
This article intends understand how are build the interactions in the class of text production and the nature of the replies in the statements of the teacher and completed students with the use of this genres of teaching. This discussion was substantiated on the dialogic theory of Bakthin(1981,1997) from which we fit the notion of responsive understanding, conforming in the applied Linguistics. For the analyze of the corpus, we use observations on the participants, video footage, and activities of the textbook "Português: Linguagens- vol.3" (CEREJA E MAGALHÃES, 2012), as others scholars works applied by teachers. The results have shown the presence of Reinteractives statements which are revealed as replicating strategies constitutive of the dialogical movements.
\end{abstract}

KEY WORDS: Responsive understanding; Dialogism; Text Production.

\footnotetext{
1 Doutora em Educação pela Universidade Federal da Bahia (UFBA). Docente Plena na Universidade Estadual do Sudoeste da Bahia (UESB). Líder do Grupo de Pesquisa Linguagem e Educação (GPLEd/CNPq).

E-mail: efigueiredo@uesb.edu.br ORCID iD https://orcid.org/0000-0001-5992-0184

2 Mestre em Letras pela Universidade do Estado da Bahia (UNEB). Docente no Instituto Federal da Bahia (IFBA).

E-mail: islenechina@hotmail.com ORCID iD https://orcid.org/0000-0003-1769-4515
} 


\section{CONSIDERAÇÕES INICIAIS}

Pensar a sala de aula como cenário discursivo pressupõe enquadrar a aula como (des)encontro de ações com e sobre a linguagem, em um processo dialógico de mobilização de diversos materiais e recursos didáticos por parte do professor e dos estudantes.

A partir da concepção de sala de aula como instância de produção e apropriação de conhecimentos e da aula assumida como gênero do discurso, propomo-nos a problematizar a aula de produção textual com o objetivo de compreender como se constituem as interações da e na aula de Língua Portuguesa. Isso se deu a partir do enquadre nos enunciados da professora e dos alunos, de modo a deslindar como a análise das estratégias docentes pode contribuir para uma ressignificação no ensino de produção de texto.

Para a consecução dessa pesquisa, mobilizamos a noção de gêneros do discurso (BAKHTIN, 1997). Além disso, a natureza social de nossa investigação permite-nos estabelecer interface com a Linguística Aplicada, ao assumir uma concepção de linguagem como prática social e formativa dos sujeitos em ação.

Para a geração dos dados, utilizamos como instrumentos a observação participante, gravação em vídeo, anotações de campo, planejamento anual da disciplina elaborado pelos professores da escola, caderno da professora e atividades realizadas pelos alunos, tanto do livro didático "Português: Linguagens" (vol. 3), dos autores Willian Roberto Cereja e Tereza Cochar Magalhães, edição 2012 do PNLD(Programa Nacional do Livro Didático), como das tarefas escolares aplicadas pela professora a partir de outros livros. Nas aulas observadas, a professora abordou o ensino de reprodução de textos dissertativos.

No escopo dos estudos realizados pelo Grupo de Pesquisa Linguagem e Educação (GPLEd/ CNPq/UESB), o artigo se constitui em um extrato de nossas inquietações como condição necessária para que os professores e professoras de português organizem suas práticas a partir desse referencial, deslocando-se de abordagens estruturais de ensino. 


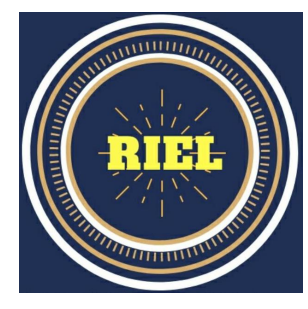

\section{GÊNEROS DISCURSIVOS: O PRESENTE NA MEMÓRIA DO PASSADO}

Ao considerar a aula como gênero discursivo, defendemos que ela possui um estilo próprio caracterizado pela ação didática de ensinar, instruir e educar. No bojo dessas ações ocorre a intercalação de elementos linguísticos que exprimem ordem, explicação e exposição com efeito didático (SOUZA; COELHO, 2016). Além disso, a aula é aqui considerada como conjunto de atividades ordenadas e articuladas (ZABALA, 1998), sendo possível afirmar que sua organização não se dá de forma rígida; mas, suscetível a intercalações entre os sujeitos da palavra, hibridismos e apropriações de outros discursos.

Nos meandros dessa organização, em seu projeto de dizer, o professor é motivado pela vontade enunciativa de ensinar determinado conteúdo e esta escolha, por sua vez, está imbuída de uma ideologia do que esse objeto representa para o professor e sua importância para os alunos. O gênero aula vai engendrar a intercalação entre outros gêneros e vozes híbridas que comporão a forma composicional e o tema da aula. Esses elementos constituem os meios pelos quais os alunos se apropriam do discurso no processo de ensino, em que se ecoam várias vozes em torno do objeto de ensino. Tais escolhas são ideológicas e, a depender de quais gêneros serão intercalados na aula, esta pode levar a uma passiva aceitação, caracterizada por revozeamento e obediência que perfazem o estilo de autoridade, ou se pode adotar um estilo internamente persuasivo, conduzindo as interações, de modo a sugerir réplicas ativas nos alunos.

A partir da composição discursiva e interacional, pode-se afirmar que a aula constitui o lugar do encontro da palavra minha com a palavra do outro, por meio dos enunciados concretos que se realizam nesse ambiente, sofrendo influência mútua. Conforme Cajal (2001), a interação é uma aprendizagem, um processo complexo e continuamente inacabado e como tal, tem suas ações direcionadas por um contexto específico. Conforme assevera Cajal(2001):

[...] na sala de aula alunos e professores constroem uma dinâmica própria, marcada pelo conjunto das ações do professor, pelas reações dos alunos às ações do professor, pelo conjunto das ações e reações dos alunos entre si, cada um interpretando e reinterpretando os atos próprios e dos outros. (CAJAL, 2001, p. 128) 
Como professores imersos nesse processo de compreensão da palavra alheia, nosso discurso didático é elaborado a partir do aluno, pois é para ele que preparamos nosso projeto de dizer, a partir do que pressupomos acerca dele e somente significamos nossa prática no momento da interação; pois o modo como nossos dizeres ecoarão definirá o andamento da aula, assim como assevera Fontana (2001):

[...] os nossos gestos e os nossos dizeres como professores não significam em si, eles significam na relação e são ativamente produzidos pelos alunos que o consomem (CERTAU, 1994). Como professores, preparamos o texto, temos no nosso imaginário um auditório social, temos intenções que modelam nossas ações e discursos, mas eles efetivamente significam na interação com as palavras daqueles que nos ouvem. (FONTANA, 2001, p. 35)

Essas ações engendradas na aula se materializam a partir da possível resposta do aluno às informações dadas pelo professor, da permissão dos alunos para falar, ou conversarem entre si, do silenciamento, da repreensão do professor. Enfim, essas ações são escolhas que delineiam o espaço de interação da aula, atribuindo sentido aos percursos enunciativos de sesu sujeitos.

Como forma de compreender melhor a forma como essas interações ocorrem, Matencio (2001) sugere um modelo de organização da aula em três etapas: introdutória (abertura e preparação), instrumental (que se constitui do seu desenvolvimento) e final (de conclusão e encerramento). Inicialmente, ocorre a abertura que tem por objetivo a interação que se inicia com a preparação para as atividades do dia e em seguida, o início efetivo da aula. Há, em seguida, o desenvolvimento das atividades e a etapa de conclusão. Por fim, a etapa responsável pelo encerramento (temporal) do encontro.

A organização da interação na aula se dá por meio de sinalizações produzidas pelos participantes da interação e acaba direcionando sempre o processo interpretativo. Essas sinalizações configuram a coconstrução de sentidos na aula. Há determinadas atividades e tarefas que podem se manifestar por meio de retomadas das respostas dos alunos pelo professor ou retomadas realizadas com preenchimento de lacunas, cujo papel é ratificar e averiguar se houve a compreensão dos alunos; o que acontece, por exemplo, quando o professor repete o dizer do aluno.

Além desse preenchimento de lacunas, Matencio (2001) aponta estratégias discursivas para viabilização das tarefas didáticas, como a retomada. Por meio dessa estratégia, pode-se criar um 
vínculo do que foi dito com o que se pretende dizer; o que pode contribuir para a delimitação do objeto de ensino, fazendo com que o estudante relembre o que foi dito.

Além da estrutura da aula sugerida por Matencio (2011), destacamos as instâncias propostas por Batista (1997), em seu livro Aula de português: discurso e saberes escolares. O autor estabelece uma divisão do plano geral da aula por meio de duas instâncias: a de produção do discurso e a instância do exercício. A primeira se realiza com prevalência da interação na esfera da oralidade, por meio da ação e reação entre o professor e o coletivo da turma; sendo pouco recorrente a interação face a face com um aluno. Já a segunda instância se manifesta por meio da interação com o objeto de ensino, sendo que o aluno responde a alguma tarefa didática proposta pelo professor, como "um texto a ser lido, um exercício a ser feito, uma redação a ser produzida, em sala ou fora dela" (BATISTA, 1997, p. 80).

A cada uma das instâncias da aula tipificadas por Batista (1997) correspondem estratégias discursivas. As primeiras são "as estratégias de organização local e intermediária do discurso" (BATISTA, 1997, p. 39), pelo enquadre da enunciação no professor, por uma pergunta feita por ele, uma resposta do aluno e finalmente uma retomada daquele à resposta do aluno, podendo ser analisada pelo padrão IRA (Iniciação - Resposta - Avaliação).

As segundas estratégias envolvem ações discursivas de "constituição dos polos da interlocução" (BATISTA, 1997, p. 201), nos quais o professor invoca a participação do aluno ou da turma com enunciados de cobrança de tarefas a cumprir, repreensões e faltas, dispersões do grupo como um todo ou de um aluno em especial. Com estes gestos de docência, o professor monitora o percurso de continuidade da aula na sua focalização com o conteúdo a ser ensinado, dirimindo a heterogeneidade presente na sala (BATISTA, 1997).

Já o terceiro conjunto de estratégias é composto pelas "estratégias de organização global da interlocução" (BATISTA, 1997, p. 62), através das quais o professor expõe oralmente o plano geral da aula, descrevendo as atividades que serão propostas para a turma.

A divisão em instância da aula e do exercício constitui apenas um modelo didático e metodológico, pois no plano discursivo as duas instâncias se revozeam por meio do agir docente com a turma, com interações globalizadas ou individualizadas, visto que ambas mantêm entre si 
uma relação dependente de constituição. São planos coconstitutivos do discurso didático que é apropriado pelo docente para expor o conteúdo de ensino, conforme sintetiza Batista (1997): “... é a alternância da realização da atividade discursiva em cada uma das duas instâncias que assegura a continuidade do discurso na sala de aula." (BATISTA, 1997, p. 95).

Considerada por Fontana (2001, p. 32) como "acontecimento de circulação de sentidos [...] postos em movimento" e sobre os quais não temos controle, a aula ocorre mesmo antes de proferimos as primeiras palavras, pois esperamos que esta aconteça de determinado modo, antecipamos o que pode reagir a nosso discurso. Nossos dizeres, gestos e ações são projetados com fins específicos que levam em conta nosso auditório social, pois sabemos que a aula é o lugar de confronto entre sujeitos com papéis sociais distintos, ocupando lugar de professor e de aluno.

Toda nossa preparação e expectativa se dirigem ao aluno, sem o qual não existiria o papel do professor que é afetado em função do perfil desse aluno; já que disso dependem nossas escolhas, nosso modo de dizer e atuar nesse cenário discursivo constituído majoritariamente por interações sociais.

Essas relações estabelecidas na aula são complexas e singulares e nos permitem remeter aos papéis ocupados por professor e aluno nas relações de aprendizagem que se instauram nesse ambiente e que vão se materializando na medida em que esses lugares vão sendo ocupados por sujeitos reais que se diferenciam em valores, crenças, etnia, sexo, idade e classe social. Essa singularidade dos indivíduos, historicamente situados, é que constitui a dinâmica da interação em sala de aula, reverberando em relações que fogem a qualquer transparência, homogeneidade ou clareza de sentidos postos nessas relações.

\section{MANIFESTAÇÕES DE RESPONSIVIDAdE NA AULA DE PRODUÇÃO TEXTUAL: ENTRE INSTÂNCIAS E ESTRATÉGIAS DISCURSIVAS}

A estruturação das aulas observadas, dispostas nos excertos 1 a 7 , se assemelhou à proposta por Matencio (2001), sendo que na etapa instrumental, a professora corrigia a tarefa solicitada na aula anterior e no encerramento propunha uma nova tarefa. Às vezes, a aula era concluída no 
encerramento mesmo, sem despedida, pois quando soava o sinal do fim da aula, os alunos já estavam em polvorosa para saírem. Foi possível perceber também que, nos dois bimestres observados, só houve explicação do gênero carta argumentativa. As outras aulas foram destinadas a atividades de interpretação de texto e tipos de argumentos para a tarefa didática de produzir textos. A professora estruturou sua aula da seguinte maneira:

a) abertura da aula por meio de saudação à turma e registro no quadro da rotina do dia;

b) preparação que solicita ou relembra dos prazos das atividades e relaciona a aula presente com a anterior ou uma das anteriores;

c) desenvolvimento das atividades constituintes daquela aula;

d) conclusão por meio de proposta de atividade a ser realizada extraclasse, como preparação para a(s) próxima(s) aula(s) e "visto" dos cadernos com a atividade corrigida;

e) encerramento do evento, com a despedida.

Essa estruturação, predominante na aula observada, corrobora a proposta por Matencio (2001). Como podemos perceber, na estrutura global elaborada pela autora, há três etapas chamadas de instrumentais: preparação, desenvolvimento e conclusão da atividade didática, em que de fato a aula se desenvolve. A abertura e o encerramento não visam ao objeto de estudo, por isso não são consideradas parte das etapas instrumentais da aula. As etapas instrumentais são configuradas, a partir de atividades didáticas que englobam as tarefas. Abaixo seguem excertos nos quais se presentificam tal estrutura:

Excerto 1 - Aula 03 (29/09/14) - Etapa de preparação da aula

1. P.: Podemos começar? Bom... nós vamos utilizar a redação já tem quinze dias que eu falei pra vocês/ trouxe a proposta... escreva sobre os feudos... construção dos condomínios de luxo os feudos da Idade Média... então ne:ssa nessa aula de hoje a gente vai utilizar esse texto pra: pra gente falar sobre os tipos de argumentos... quem tiver com o livro e quiser abrir pra dar uma acompanhada no livro de vocês na página duzentos e oitenta e SEIS a duzentos e oitenta e OITO ((a professora folheia o livro abrindo na página indicada)) tem os tipos de argumentos que costu::mam/ podemos utilizar na construção de texto 


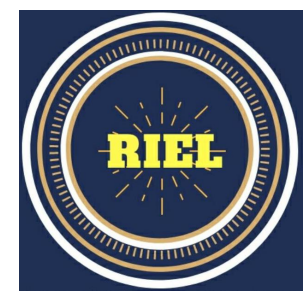

argumentativo... OK? Então vamos lá... primeiro tipo de de argumento utilizado é a comparação... no texto que a gente leu na aula anterior que corrigimos as atividades... o texto gravidez na adolescência faz uma comparação qual é? Me expliquem... o que que é comparado logo no início?

Excerto 2: Aula $02(22 / 09 / 14)$ - Etapa de desenvolvimento da aula

2. P.: o artigo de opinião também ele é argumentativo... também tem uma/ o que você defende no artigo? Você defende uma tese: [A1: posição]uma posição. Na dissertação expositiva: sobre a redução da maioridade penal eu posso dizer o que é a redução... como ela acontece no BraSIL... ONde ela acontece de outra forma... SEM ne-ces-as-ria-men-te dizer que sou a favor ou contra.

No excerto 1, foi possível perceber a etapa de preparação e início do desenvolvimento da aula, em que a professora retomava a tarefa solicitada anteriormente e depois pedia aos alunos para abrirem o livro na página em que constavam alguns tipos de argumentos. No excerto 2, a professora já estava na etapa de desenvolvimento, fazendo retomada ao que foi tematizado anteriormente.

No que tange à ocorrência da conclusão e do encerramento, mostraremos o excerto 3 da aula 02 (22/09/14), no qual se evidencia a conclusão com a marcação de tarefa do livro e entrega de material impresso para realização em casa, ou a finalização da correção de exercício, seguida dos vistos nos cadernos daquela tarefa corrigida.

Excerto 3: Aula 02 (22/09/14) - Etapa de conclusão e encerramento da aula

3. P.: adianta? tá bom... quem ainda não fez a redação escreve/ leia essa parte do livro da página duzentos e oitenta e seis a duzentos e oitenta e oito... observem shhh... observem os eXEMplos... quem já fez analisa sua redação a parte do desenvolviMENTO olhando aí esses tipos de arguMENTO e quem/ e quem ainda NÃO FEZ tem uma segunda CHANCE.

((( alguns alunos tiram dúvida com a professora indo até sua mesa e em seguida ela encerra a aula))

4. P.: ok? até segunda

Além da proposta de estruturação da aula realizada por Matencio (2001), Batista (1997) apresenta possibilidadede se analisá-la, abarcando duas instâncias: a da aula e do exercício. Como já discutido na seção 2, o autor focaliza a organização da aula e estabelece três estratégias na instância 


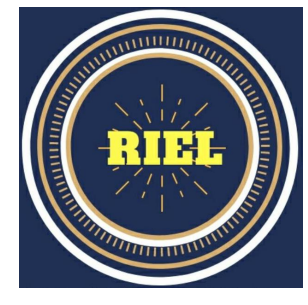

da aula, sendo estas "as estratégias de organização local e intermediária do discurso", "as estratégias de constituição dos polos da interlocução" e "estratégias de organização global da interlocução".

Nas aulas observadas, verificamos que a instância do exercício se realiza por meio de tarefas solicitadas para casa em que o interlocutor do aluno é constituído pelo autor do material didático. A partir dessas considerações, constatamos que prevalece, nas aulas de produção textual, a instância da aula; porém, como pontua o próprio Batista (1997): elas se encontram imbricadas, posto que a correção da tarefa feita em casa era corrigida na aula seguinte. Quanto às estratégias utilizadas pela professora na instância da aula, nos excertos 4,5 e 6 constam alguns exemplos:

Excerto 4: Aula 03 (29/09/14) - Estratégia local de organização da aula

4. P.: (...) o ponto cinco.../ o ponto cinco da xerox fala sobre a conclusão... TIpos de com-clu-são que também a gente estudou... pode ser a concluSÃO:? que tipos de conclusão?

5. Gr.A.: Síntese ou resumo...

6. P.: SÍNtese ou resumo em que você conDENsa... sintetiza as ideias discutidas no desenvolvimento confirma... pode ser a retomada da tese em que você reafirma o seu posicionamento aqui na tese com outras palavras obviamente... e para a redação do ENEM o-bri-ga-to-ria-MEN- te há solução para o problema... dos mil pontos a conclusão vale duzentos... apresentar uma proposta de solução para o problema que seja viável... que seja execuTÁvel... que tenha Lógica e resPEIte os direitos humanos.

A professora iniciou essa aula, apresentando distinções entre gêneros argumentativos, retomando aqueles já abordados e, em seguida, corrigiu uma atividade. Durante a correção, pudemos constatar que alguns alunos não responderam à atividade, visto que só se perguntava se era adequado ou inadequado, conforme solicitado na tarefa.

Ao perguntar sobre o tipo de conclusão da questão do exercício, a professora ratificava a resposta considerada correta, repetindo a resposta e/ou complementando-a.

No excerto 5, verificamos a estratégia do estabelecimento dos polos de interlocução, quando a professora requisitou o silêncio da turma por meio de diversas expressões. 
Excertos 5 e 6 - Estratégia de constituição dos polos da interlocução - Aula 03: 9/09/14 e Aula 06:

$18 / 11 / 14$

5. 1. P.: Podemos começar? Bom... nós vamos utilizar a redação já tem quinze dias que eu falei pra vocês.

6. 1. P.: Psiu... tô esperando... ei A. tá mexendo no celular aí Alex?((A professora organza seus materiais e para em pé em frente à turma encarando alguns alunos que estão conversando até que chama atenção de alguns para que ela pudesse começar a aula))

Nesses fragmentos fica evidenciado que a professora referiu-se à conversa entre os alunos expressando repreensão, esperou em silêncio e, posteriormente, chamou alguns alunos por nome ou perguntou se já poderia iniciar, aguardando, assim, a tomada de posição dos alunos:

Excerto 6 - Estratégia de organização global da interlocução Aula 02: 22/09/14

6. 32. P.: conferindo:: a unidade começou dia dez e vai terminar no dia vinte de janeiro... a gente tem conteúdo carta ARGUMENTATIVA... nós teremos duas avaliações nessa unidade... a primeira avaliação é a produção de uma carta argumentativa no dia primeiro de dezembro valendo cinco pontos... a segunda avaliação será a prova final da quarta unidade que será no dia:: doze de janeiro... GENTE POR FAVOR... é pra conferir no caderno quem anotou e quem não anotou também... anota né? As notas do caderno ficarão de ponto extra CA-SO necessário JÁ QUE a gente não tem paralela na quarta unidade... em nenhuma disciplina VIU? (....)vocês já sabem que a prova de TD é feita antes da semana de prova das outras disciplinas né? (...) Dia dezenove resultado da disciplina... quem passou: quem ficou de recuperação... a prova de recuperação dia VINTE E UM de janeiro...

\section{$[\ldots]$}

183. P.: adianta? tá bom... quem ainda não fez a redação escreve/ leia essa parte do livro da página duzentos e oitenta e seis a duzentos e oitenta e oito... observem shhh... observem os eXEMplos... quem já fez analisa sua redação a parte do desenvolviMENTO olhando aí esses tipos de arguMENTO e quem/ e quem ainda NÃO FEZ tem uma segunda CHANCE.

No excerto 6 (turno 183), a Professora (P) finalizou a correção da atividade e relembrou os alunos da produção solicitada e o prazo para a resolução que seria na próxima aula. Foi orientado, inclusive, que havia subsídios no próprio livro didático para a seleção dos tipos de argumento a 
serem utilizados. No primeiro turno da aula 03 desse mesmo excerto, a professora iniciou a aula solicitando a produção que seria utilizada naquela aula, parafraseando seu próprio dito de quinze dias atrás, o que garantiu a progressão discursiva da sequência abordada por ela.

Aula 03: 19/09/14

1. P.: Podemos começar? Bom... nós vamos utilizar a redação já tem quinze dias que eu falei pra vocês/ trouxe a proposta... escreva sobre os feudos... construção dos condomínios de luxo os feudos da Idade Média...

As estratégias discursivas aqui explicitadas, como pertencentes à instância da aula, foram produzidas previamente e parte do pressuposto de que o aluno, individualmente, realizaria as atividades propostas pelo(a) professor(a), seja em forma de perguntas realizadas em um estudo de texto, das instruções de uma atividade, seja por meio de uma avaliação ou uma produção textual.

Tais atividades supunham como polos do discurso não o professor e a turma como um todo, mas esta com o material escrito, pelas instruções da atividade. Tal instância é denominada por Batista (1997) como instância do exercício, pois é organizada “... em torno de um conjunto de textos escritos, partilhados entre si, em grande parte, fornecidos pelo livro didático.” (BATISTA, 1997, p. 80). Desse modo, os alunos constroem relações, objetivos e estratégias nessa instância e por outro, esses textos também estabelecem os "horizontes de interlocução" realizados na instância da aula, sendo um dos recursos para o que foi abordado em sala ou do que será mais explorado.

No excerto 7, a execução prévia das atividades propostas pela professora foi importante para a progressão da aula, conforme o planejamento docente. Nesta aula, a professora entregou algumas atividades avaliativas para os alunos, esclareceu sobre as avaliações e pontuações da unidade do ano letivo e as datas previstas para cada uma delas. Posteriormente, introduziu o objeto de ensino carta argumentativa, comentando suas características estruturais. Por fim, encerrou a aula com a correção da atividade solicitada por outra professora em aula anterior.

No excerto 7, percebem-se dois momentos em que são corrigidas as tarefas e como se distingue o andamento da aula. 


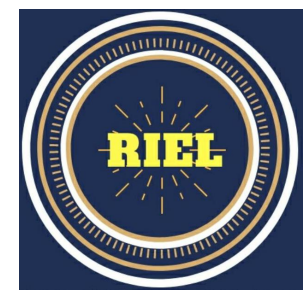

Excerto 7: Aula 06 (18/11/14) - Instância do exercício

33. P.: [...] e esta primeira/ a primeira atividade passada na aula passada foi uma carta de leitor... cinco cartas na verdade são cartas ...de cinco leitores com cinco temas diferentes ... seis leitores sobre cinco temas diferentes e que:: Oi? é do livro ... eu pedi que trouxessem o livro... na sexta-feira eu pedi que trouxessem o livro... a gente tem/ ((faz uma pausa aguardando o silêncio da turma)) página cento e cinquenta e quatro. gente::: psiu nesse livro a gente tem duas atividades sobre carta argumentativa e primeira delas é carta de leitor e a outra a gente vai usar posteriormente... nesta atividade: ((para e olha para um aluno que conversa e fica em silêncio por alguns segundos))a gente tem aqui no início cinco de seis leitores sobre cinco temas que foram publicados em jornais e revistas... o leitor: ao ler a reportagem QUIS se manifesTAR e fez isso através de uma carta... escreveu a carta pra edição/ pra/ pra o editor da revista ou do jornal ELOGIANDO... reclamANDO... sugeRINDO... que sao possiblidades de o leitor ao ler uma matéria... no caso do exercício... shhh... fizeram a atividade da aula passada? quem não fez na aula fez ao longo da semana... podemos CORRIGIR?

34. Aa.13: [Hoje de novo?]

35. Aa.14: que página?

36. P.: ((a professora vai falar sobre a organização das atividades do livro de acordo com o assunto)) Fizeram? ...shhh... Fizeram o exercício fizeram a atividade da aula passada quem não fez na aula fez ao longo da semana? Tá...pronto podemos corrigir?

37. Aa.15: Nããããaooo professora dá dois minutos aí

38. P.: nããooo não não ... Vocês tiveram terça quarta quinta... sexta ... mas teve um colega aqui a sala ...

39. Aa.15. Que colega é esse ?

40. P.: shhhh ... Ó: gente quem não VEM é que tem que providenciar o que foi que você perdeu... não é assim não.

((Começa a se exaltar quando vê que a turma não fez a tarefa))

41. Aa.16. Também acho

42. P. Então ... Uma semana depois pra ver a aula ... passada e só hoje é que tô sabendo o que aconteceu? não é assim não ... quem não veio segunda- feira é que tem que perguntar na terça... Shhhhh... ESCUTA tinha que perguntar pro colega que veio na terça o que foi que teve na aula ... teve aula ou não teve ? Foi aula vAGA? se não foi aula vaga alguma coisa teve o que foi que teve? ... vou passar agora vistando... quem não fez na aula passada teve uma semana para fazer (( em seguida a professora vista as atividades de quem fez )) podemos começar? vamos lá ... por favor quem está com outro material ou conversa paralela... hoje já deu passou do LIMITE... daqui pouco bate mas enquanto não bate ... enquanto a aula não bate vamos começar a correção...

(( Alguns alunos protestam, falam que não postaram no grupo, mas em geral os alunos conversam simultaneamente e não dá para entender))

$[\ldots]$

79. P.: segundo texto segunda etapa ... quem é NFF de SP() terceira carta lembra? é a carta que fala sobre a Amazônia ()... A ... na sessão frases dizia não vamos ficar parados vamos agir está entre aspas está fala foi tirada de onde ? de uma matéria publicada né ? ele tá fazendo referência nesse texto a ... à destruição da floresta Amazônica contemplando a fala desse menino

80. A.: 15: já bateu professora

81. A.22: já bateu dez e cinquenta e sete 
Os turnos mostram que alguns alunos deixaram de realizar a tarefa da aula anterior e isso gerou um corte na progressão da aula (turnos 33 a 42), o que não ocorreu em outras aulas. Alguns alunos não responderam e acabaram ficando dispersos na aula, ansiosos para ir embora; como se constata nos turnos 81 e 82 . Esse fato mostra que grande parte da interlocução efetivada na instância da aula provém da organização dos textos em torno dos quais se efetiva a instância do exercício, cuja progressão depende de como esta foi viabilizada na instância da aula. Percebemos aí que a heterogeneidade e a dispersão ocorreram, em parte, pela não concretização da tarefa proposta.

No que se refere aos textos escritos utilizados pela professora, na instância do exercício, foram advindos tanto do livro didático como de materiais selecionados pela professora em cópias para os alunos. Uma das tarefas propostas foi a atividade das páginas 284 a 286 do livro didático adotado, que consistia na leitura e resolução de questões sobre o texto: "Gravidez na adolescência". Essa atividade fazia parte da seção do livro: Produção de texto que apresentava um texto com questões para interpretação, cujo enfoque se concentrava em tipos de argumento. Na sequência, havia uma proposta de produção com um texto de base e por fim, alguns aspectos de coesão e coerência abordados por meio de exercício de leitura.

Nos exercícios posteriores, contidos no livro didático de português, a estrutura era recorrente. Nesses exercícios eram contemplados aspectos como veiculação do texto, finalidade e elementos estruturais constitutivos do gênero; sem considerar, no entanto, a discursividade do texto.

Por isso, concordamos com Bakhtin (1997) quando afirma que:

[...] em todos esses casos, não lidamos com a palavra isolada funcionando como unidade da língua, nem com a significação dessa palavra, mas com o enunciado acabado e com um sentido concreto: o conteúdo desse enunciado. A significação da palavra se refere à realidade efetiva nas condições reais da comunicação verbal. É por esta razão que não só compreendemos a significação da palavra enquanto palavra da língua, mas também adotamos para com ela uma atitude responsiva ativa (simpatia, concordância, discordância, estímulo à ação). (BAKHTIN, 1997, p. 310).

Ao considerar o diálogo na concepção de Bakhtin (1997) e seus estudos sobre gênero do discurso, acreditamos que faltavam nessas seções, aspectos discursivos como o perfil do 
interlocutor, aspectos estilísticos que diferenciassem o gênero, como o interlocutor imaginaria seu destinatário e as estratégias utilizadas para convencê-lo (no caso do texto argumentativo). Nos gêneros complementares das atividades do livro, constavam diferenciações entre os gêneros artigo de opinião, dissertação-argumentativa e carta argumentativa, bem como aspectos da estrutura da dissertação e da carta argumentativa.

A aula era constituída por uma série de atividades que a organizavam e garantiam a síntese ou análise de algum objeto de ensino, bem como a sequência por elas estabelecida formavam um elo na corrente maior desse discurso.

\section{CONSIDERAÇÕES FINAIS}

Como o foco do trabalho na aula de produção textual se concentrava nos argumentos, em detrimento de aspectos como: quem seria seu interlocutor, para que finalidade se produziria tal texto, em que condições seria produzido; aspectos discursivos importantes para a elaboração e delimitação do gênero.

Como na aula circulam diversas esferas de produção da linguagem: a oral, a escrita e a verbovisual; os enunciados da professora e dos estudantes, entendidos como gêneros do discurso, carregam traços peculiares à situação argumentativa que buscaram atender à produção do texto argumentativo.

No contexto mais amplo do domínio da forma composicional do gênero, os estudantes revelaram conhecer a estabilidade relativa do gênero abordado, sendo ratificada essa compreensão pela professora, pois assumia o propósito de enunciar intenções das atividades sociocomunicativas dos discursos produzidos na aula.

O repertório de gêneros de natureza argumentativa a ser apropriado pelos estudantes se ampliou com a ação pedagógica da professora, à medida que ela direcionava e problematizava os enuciados do livro didático, das tarefas apresentadas e dos próprios questionamentos dos estudantes. Essas ações docentes eram recorrentes e já do conhecimento da turma, mas também podiam 
perspectivar dimensões novas na dinâmica discursiva da aula de se constituirem entre o que já foi e é dado, com o que é novo.

Conforme o pensamento bakhtiniano, como tipos enunciativos relativamente estáveis, os gêneros cumprem funções sociocognitivas e organizam a comunicação humana. No interior da aula assumem entoação didática, enquandrando a compreensão e a resposta ativa à atividade escolar proposta pela professora. Seja como reprodução do discurso docente, seja como resposta a um novo modo de ver e criar a realidade, a produção textual, como produto de uma aula de português, possibilita apreender matrizes genéricas para gerar resposta portadora de sentidos à atividade proposta.

\section{REFERÊNCIAS}

BATISTA, A. A. Aula de português: discurso e saberes escolares. São Paulo: Martins Fontes, 1997.

BAKHTIN, M. Estética da criação verbal. São Paulo: Martins Fontes, 1997.

CAJAL, I. B. A interação de sala de aula: como o professor reage às falas iniciadas pelos alunos? In: COX, M.I.P., ASSIS-PETERSON, A. A. (Orgs.). Cenas de sala de aula. Campinas: Mercado das Letras, 2001.

Cereja, W.; MAgAlhãeS, T. C. Português: Linguagens. 7ed. v. 3, $3^{\circ}$ ano do Ensino Médio. São Paulo: Saraiva, 2010.

FONTANA, R. A. C. Sobre a aula: uma leitura pelo avesso. Revista Presença Pedagógica. v. 7 no 39. Belo Horizonte: Editora Dimensão, maio /junho de 2001.

MATENCIO, M. L. M. Estudo da língua falada e aula de língua materna: uma abordagem processual da interação professor/alunos. Campinas: Mercado de Letras, 2001.

SOUZA, E. M.F. Indagações acerca do enunciado concreto. In: SANTOS, E. (Org.). Transdiscursividades: linguagem, teorias e análises. Salvador: EDUFBA, 2012.

SOUZA, E. M. F.; COELHO, F. C. B.; A docência como objeto de discurso: contrapontos entre linguagem e educação. In: SOUZA, E. M. F. (Org.). Letramento e dialogia: enfoques para a formação de professores. Vitória da Conquista: Edições UESB, 2016.

ZABALA, A. A prática educativa: como ensinar. Porto Alegre: Editora Artes Médicas Sul Ltda., 1998. 